\title{
A profundidade histórica dos fluxos
}

Dias, Juliana Braz \& Lobo, Andréa de Souza (Orgs.). África em movimento. Brasília, ABA Publicaçóes, 2012, 300 pp.

\author{
Rocío Alonso Lorenzo \\ Universidade de São Paulo
}

Esta coletânea de artigos, organizada por Juliana Braz Dias e Andréa de Souza Lobo, apresenta-nos uma visão das teorias da globalização crítica e refrescante, que oxigena algumas convicçóes excessivamente comemoradas na década de 80 e que, pelo jeito, começam a soar ilusórias. No contexto de "mobilidade" social e espacial da África contemporânea e do "embrionário" campo de estudos africanistas brasileiro, as autoras e autores dispóem-se a responder criativamente ao que Wilson Trajano Filho na introduçáo do livro chama de "percepçáo ilusória de novidade". Expressão cunhada por João de Pina-Cabral, remeteria a um suposto "uso e abuso" por parte das teorias da globalização de uma "miríade semântica" de conceitos como "desterritorialização, transnacionalizaçáo, transmigrantes, hiperespaços, espaços hiper-reais e globais” (p.10), que teriam sido erroneamente tomados por fenômenos novos que só passaram a existir a partir do final do século Xx. Como contrapartida ao excessivo "presentismo" e à "obsessáo" por fluxos de coisas, ideias e pessoas, Dias e Lobo sugerem focalizar o "movimento" como "um elemento estrutural, com profundidade histórica" e apontam o uso de formas narrativas - obras literárias, filmes, músicas e fotografias - como estratégia metodológica. Sem pretender desvalorizar a qualidade etnográfica dos trabalhos coletados no livro, vale a pena, no entanto, alertar sobre o risco de tomar a "cultura popular" como monopólio da análise dos 
REVISTA DE ANTROPOLOGIA, SÃO PAULO, USP, $20 \mathrm{I}$, V. $58 \mathrm{~N}^{\mathrm{O}} \mathrm{I}$.

"movimentos". Terreno este, assim como os ditos "fluxos", "sacralizado" pelas teorias da globalização, principalmente por aquelas influenciadas pela crítica cultural e o pós-modernismo.

Sem dúvida, o capítulo introdutório de Trajano Filho quebra essa armadilha, passando a propor a perspectiva de Ulf Hannerz (1987) da "crioulização" linguística como aquela que forneceria ao antropólogo uma "matriz-raiz" para pensar nos fluxos culturais e na transformação das estruturas de significação que as sociedades da periferia fazem das culturas metropolitanas. Ainda, o autor identifica criticamente quatro tipos de "abusos" que afetariam negativamente a análise de "fluxos e movimentos em África". Em primeiro lugar, o "presentismo" ou "engano subjacente" dos estudos sobre a globalização de que haveria uma "ruptura histórica" que libertaria as pessoas de um suposto "aprisionamento das localidades" (p. 25). Em segundo lugar, o excesso de atenção por parte dos estudos "diaspóricos" a fluxos unidirecionais que acontecem majoritariamente da periferia para a metrópole, sendo que "quando se trata de fluxos de objetos e valores, a unidirecionalidade se inverte do centro para a periferia" (p. 33). Em terceiro lugar, ao tomar os "fluxos intersocietários de larga escala" como foco principal, a literatura sobre fluxos estaria obscurecendo "movimentos microscópicos", que teriam um papel importante na conformação de culturas concretas. Por fim, o quarto tipo de "abuso" aponta para os "sistemas inerciais", ou "sistema referencial de quem observa”, como responsáveis pela produção de conceitos e olhares profundamente marcados pelas grandes tradiçóes acadêmicas africanistas, como a anglófila versus francófila. Trajano Filho ainda levanta alguns questionamentos e preocupações a respeito dos "ainda embrionários estudos africanos" no Brasil, como o excessivo localismo das pesquisas, a falta de uma formação africanista sistemática, a preferência dos pesquisadores de temáticas soft como a cosmologia e a religião, tão susceptíveis de serem capturadas por essencialismos metafísicos, e o risco de exportar modelos sul-americanos para a África. 
REVISTA DE ANTROPOLOGIA, SÃO PAULO, USP, $20 \mathrm{I} 5$, V. $58 \mathrm{~N}^{\mathrm{O}} \mathrm{I}$.

A coletânea de artigos abre-se com uma primeira parte intitulada "Movimento como Valor". No primeiro capítulo, "Manera, ess Muv?": a mobilidade como valor em São Vicente de Cabo Verde", João de Vasconcelos propóe entender a "mobilidade" como tendo um duplo valor, instrumental e moral. Vasconcelos baseia-se em poemas de Baltasar Lopes da Silva, poeta e ensaísta cabo-verdiano que recebeu importantes influências de Gilberto Freyre, assim como em cançôes (mornas) compostas ao longo do século $\mathrm{xx}$, captando de maneira delicada e audaz o que diz ser uma tensăo "entre o valor do fazer-se a vida pondo-se em movimento e o valor dos relacionamentos locais [...] como fonte de 'conflito psicológico' e de 'inquietação' existencial" (p.58).

No segundo capítulo, "Vidas em Movimento. Sobre mobilidade infantil e emigração em Cabo Verde", Andréa de Souza Lobo analisa a "circulaçáo de crianças" entre familiares, vizinhos ou amigos na ilha da Boa Vista, uma dentre as nove ilhas que compóem o arquipélago caboverdiano. A "circulação de crianças" acontece, sobretudo, no contexto dos fluxos migratórios de mulheres que partem para a Itália em busca de oportunidades de emprego, inserindo-se no próprio ethos transnacional que marca a identidade cabo-verdiana. Inspirando-se no conceito de relatedness de Janet Carsten (2000), Lobo assinala "uma abertura para idiomas indígenas de conexão" (p.69) que vão além das relaçốes de parentesco. A frequência dessa mobilidade, não livre de tensōes, é compensada por um conceito de maternidade social e de "matrifocalidade" que inclui várias geraçóes, estabelecendo uma tríade entre emigrante, filho ou filha e família receptora, que é mediada pela comunicação à distância e a troca regular de informaçôes, objetos, recursos e afetos, os quais devem ser regularmente acionados.

No capítulo terceiro, "Música Cabo-verdiana, Música do Mundo", Juliana Braz Dias analisa como o gênero da morna passou a circular pelo mundo sob a categoria de world music ("músicas do mundo"), criada na 
REVISTA DE ANTROPOLOGIA, SÃO PAULO, USP, $20 \mathrm{I}$, V. $58 \mathrm{~N}^{\mathrm{O}} \mathrm{I}$.

década de 1980 pela indústria discográfica internacional e que teve como sua principal protagonista a cantora cabo-verdiana Cesária Évora. Apesar da influência dos critérios rígidos que definem o estilo world music, a autora argumenta que algumas características estruturantes tanto do gênero morna quanto do contexto no qual as mornas se originaram, fazem destas "a manifestação da música cabo-verdiana que mais facilmente permite uma negociação entre proximidades e distâncias” (p.91), expressando de maneira muito particular a ambivalência entre a dor da saída e o prazer do regresso do emigrante.

A segunda parte do livro, intitulada "Fluxos e Refluxos", abre-se com o texto "Gênero, Missão e Retorno: passado e futuro da Igreja Kimbanguista em Lisboa”, coautorado por Ramon Sarró e Joana Santos, que trata da trajetória desse movimento cristão desde suas origens até o momento atual. O kimbanguismo teria sido fundado em 1921 na região do Baixo Congo, atual República Democrática do Congo, pelo líder espiritual Simon Kimbangu (1887-1951), que passou a ser entendido pela teologia kimbamguitsta como o Paracleto, o Espírito Santo que ficara entre a humanidade para a eternidade. Apesar de o líder ter sido preso pelas autoridades desde 1921 até sua morte em 1951, a esposa Mamá Mwilu e seus três filhos teriam dado continuidade ao kimbanguismo, uma vez que a Igreja foi reconhecida pelos belgas em 1959, transformando-se numa das maiores denominaçôes religiosas do Congo independente e se espalhando por alguns países europeus por meio da diáspora angolana e conguense. Partindo de uma "antropologia do evento", analisa-se o processo pelo qual a comunidade kimbanguista lisboeta acaba adquirindo um reconhecimento público do qual outras comunidades kimbanguistas da Europa carecem. Contudo, ideias de retorno à terra natal e discursos políticos messiânicos começam a surgir no contexto de crise econômica vivido atualmente na Europa, surgindo tensôes entre as "forças centrífugas" diaspóricas e as "forças centrípetas" que convergem para N'kamba-Nova Jerusalém. 
REVISTA DE ANTROPOLOGIA, SÃO PAULO, USP, $20 \mathrm{I} 5$, V. 58 No I.

Numa análise etno-histórica não livre de detalhes, Milton Guran, em "O Refluxo da Diáspora Africana em Perspectiva: Angola, Benin, Togo, Nigéria, Gana, Libéria e Serra Leoa”, descreve as circunstâncias que rodearam o retorno de africanos da dita diáspora das Américas ao continente de origem durante todo o século XIx, focando na especificidade do caso dos agudás do Benin. O "retorno" resulta na seguinte contradição: "os africanos da diáspora, ao perderem sua cidadania e o seu pertencimento às sociedades de origem, passam a ser considerados como 'o outro'” (p. 130). No entanto, os agudás do Benin, ou escravos retornados "brasileiros" e seus descendentes, teriam conseguido construir uma nova identidade associando-se aos antigos traficantes brasileiros. A história é fascinante, começando com o traficante Francisco Félix de Souza, nascido na Bahia em 1754, quem teria costurado cuidadosamente uma dinastia que perdura até hoje a partir do casamento com princesas do reino Guin e outros relacionamentos com mulheres nativas, chegando a gestar uma prole de sessenta e três filhos e a usufruir o título de vice-rei de Uidá ou Chachá, o qual concedia-lhe "o direito de monopólio sobre todo a tráfico de escravos no reino do Daomé” (p.135). Graças à família de Souza, os agudás adquiririam a "qualidade de cidadáos de plenos direitos", constituindo uma exceção entre os escravos retornados na África Ocidental.

Dos agudás passa-se ao "Uso e Abuso do Afro do Brasil na África", onde Livio Sansone discute o processo de patrimonialização da Cidade Velha, antiga capital da colônia, situada na Ilha de Santiago em Cabo Verde. Sansone salienta algumas tensóes, paradoxos e estranhamentos que teriam surgido a partir do reconhecimento pela Unesco da cidade como Patrimônio da Humanidade em 2009. Se, por um lado, essa patrimonialização "por cima" e "de fora para dentro" (centrípeta) abriria novas oportunidades de investimentos turísticos, por outro lado, o processo envolve a busca de elementos "diferentes" dignos de serem protegidos de acordo com o modelo de "diversidade cultural" e "multicultural" 
REVISTA DE ANTROPOLOGIA, SÃO PAULO, USP, $20 \mathrm{I}$, V. $58 \mathrm{~N}^{\mathrm{O}} \mathrm{I}$.

promovido pela Unesco, no qual a mestiçagem, ou a crioulização, não teria lugar. Ironicamente, elementos da cultura afro-brasileira como a capoeira e a estética afro dos blocos carnavalescos soteropolitanos teriam sido importados às ilhas cabo-verdianas, constituindo-se em fonte de inspiração para a "redescoberta" ou revitalização de elementos africanos da própria ilha de Santiago.

A terceira parte do livro, "Projetos Migratórios, Pertencimento e Exclusão", abre-se com um texto de Lorenzo Macagno que aborda a diáspora chinesa moçambicana, conhecida também como "luso-chinesa" ou "sino-moçambicana”. O capítulo "Os 'Chineses' da Beira, Moçambique. Itinerários de uma dispersão” reflete sobre as forças históricas e sociopolíticas contraditórias que levaram essa comunidade chinesa, de aproximadamente oitocentas pessoas, a serem adulados pelo poder colonial português como comunidade "simpática" e amiga e serem objeto de perseguiçôes por parte do governo moçambicano e dos partidos independentistas de esquerda, uma vez que a guerra de independência de Moçambique iniciara-se entre final da década de 60 e início da década de 70. $\mathrm{O}$ autor explora, a partir de entrevistas realizadas com chineses vindos da Beira e estabelecidos em Curitiba, como alguns deles tiveram que assumir uma "cidadania flexível", parafraseando a expressão cunhada por Aihwa Ong (1999), ao mesmo tempo que enfrentam a tendência da Portugal "europeia" atual a negar a renovação da nacionalidade portuguesa a muitos desses brasileiros naturalizados.

Um ensaio curto de Kelly Silva, "Sobre Pretéritos e Afetos, algumas Inquietaçôes e Provocaçôes", toma o tema da imigração e um documentário de Teresa Prata baseado na obra do romancista moçambicano Mia Couto como referências para refletir sobre as tensóes vividas a partir dos "silenciamentos impostos" pelas guerras coloniais. Essas tensôes são reivindicadas pela autora como merecendo uma "dignidade analítica" ainda não muito explorada. 
REVISTA DE ANTROPOLOGIA, SÃO PAULO, USP, $20 \mathrm{I} 5$, V. 58 No I.

Este bloco temático sobre migraçóes encerra-se com um texto etnográfico de Pilar Uriarte Bálsamo, "Diáspora Africana e Navios de Carga na Modernidade: um estudo das migraçóes irregulares desde a África Ocidental ao Cone Sul", onde a metáfora do "navio" - ou o primeiro "cronótopo moderno" na linguagem de Paul Gilroy (2001) - é acionada pela autora para pensarmos nas experiências de viagem dos "polizones". Termo tomado do espanhol e que se refere à "forma de viajar do clandestino, sem documentação e/ou sem passagem, escondido em barcos e, por extensão, em outros meios de transporte" (p. 210), os polizones são abordados por Bálsamo como "sujeitos ativos" que não abandonam "a ideia do deslocamento como estratégia de inclusão social”. O risco - o "perigoso é nâo correr perigo" - aparece na interpretação audaz da autora como elemento constitutivo das experiências migratórias intercontinentais empreendidas por jovens emigrantes africanos, e principalmente da África Ocidental, que sonham com ir à Europa ou aos Estados Unidos, mas que, por "acidente" ou por falta de opçóes, acabam se estabelecendo na América do Sul. Chama a atenção o fato de esses longos percursos transoceânicos serem gestados entre amigos e grupos de pares, em contraste com os deslocamentos intrarregionais, dentro do continente africano, os quais envolveriam redes familiares na sua grande maioria.

A parte IV do livro, "Metodologias em Trânsito", abre-se com um ensaio curto de Claudia Bongianino, Denise da Costa e Sara Morais que retoma o debate sobre formas violentas de migração a partir do cinema realizado por uma geração de cineastas africanos como Sembène Ousmane, Med Hondo, Desiré Ecaré, Safi Faye, Moustapha Alassane, Abderrame Sissako, Oumarou Ganda, Jacques Champreux, entre outros, e que começaram as suas carreiras nas décadas de 60 e 70, uma vez que seus respectivos países se tornaram independentes. Trata-se, grosso modo, de um tipo de cinema que usa a própria violência como linguagem com o fim de alarmar a quem assiste. 
REVISTA DE ANTROPOLOGIA, SÃO PAULO, USP, $20 \mathrm{I}$, V. $58 \mathrm{~N}^{\mathrm{O}} \mathrm{I}$.

Reflexôes sugestivas e chocantes sobre a "reconstrução" do patrimônio afro-brasileiro são trazidas por Antonio Motta, num capítulo intitulado "Da África em Casa à África fora de Casa (Notas sobre uma exposição em trânsito)", a partir da experiência do próprio autor na realização de uma exposiçáo gráfica que envolveu afro-brasileiros e estudantes africanos residentes no Brasil e que surgiu no contexto de revitalização do Museu da Abolição de Recife, criado pelo governo brasileiro em 1954 e reaberto ao público só em 2012 com o objetivo de representar a presença do Negro na sociedade brasileira. Num tom sincero, o autor relata a experiência por ele vivida no "processo de discussão e disputa através do qual a narrativa expográfica foi sendo construída” (p. 247). Os participantes africanos, ao total trinta e três estudantes procedentes de diversas áreas de conhecimento e universidades brasileiras, confrontaram o que consideravam uma visão romântica, a dos afro-brasileiros, de uma "reserva cultural” derivada da escravidão inexistente na África contemporânea. Como solução final ao tal "descompasso" de temporalidades e espaços, realizou-se uma exposição em que as duas visóes, a África "de dentro" e a África "de fora", foram representadas.

João de Pina-Cabral encerra o livro com um texto excepcional em relação à linha temática e estilo narrativo dos outros capítulos do livro. "Um livro de Boa Fé? A contraditoriedade do presente na obra de Henri-Alexandre Junod (1898-1927)" é uma viagem introspectiva à vida e obra de Junod, um missionário suíço que conviveu entre os Tsonga da África do Sul e que produz textos etnográficos e românticos sobre os seus costumes. Pina-Cabral toma a obra de Junod como pretexto para refletir sobre a ambivalência entre um presente inacabado, "a ser destruído", e uma narrativa etnográfica "não ficcional", porém contraditória, onde o julgamento do "Paganismo" se faz possível uma vez que iria desaparecer.

África em movimento é um livro não só para antropólogos africanistas, senão também para historiadores, cientistas sociais e críticos culturais 
REVISTA DE ANTROPOlOGIA, SÃo PAULO, USP, 2015 , V. 58 No I.

que queiram repensar os "usos e abusos" da miríade de esnobismos que as tão comemoradas teorias da globalizaçáo tomaram como tropos explicativos das ditas diásporas pós-coloniais, esquecendo a "profundidade histórica" e "ambivalências" que dão sentido aos "movimentos", mesmo quando estes implicam processos de "desterritorialização" e de ruptura com o passado.

\section{Referências bibliográficas}

Carsten, Janet

2000 Cultures of Relatedness: New Approaches to the Study of Kinship. Cambridge, Cambridge University Press.

HANNERZ, Ulf

1987 "The World in Creolization". Africa, 57 (4): 546-559.

ONG, Aihwa

1999 Flexible Citizenship. The Cultural Logics of Transnationality. Durham e Londres, Duke University Press.

Gilroy, Paul 